\title{
Biomarkers in Neonatology: The Next Generation of Tests
}

\author{
Pak C. Ng Hugh S. Lam \\ Department of Paediatrics, Prince of Wales Hospital, The Chinese University of Hong Kong, Hong Kong, SAR, China
}

\section{Key Words}

Biomarkers $\cdot$ Newborns $\cdot$ Nucleic acids $\cdot$ Organ-specific biomarker

\begin{abstract}
Over the past two decades, neonatal clinicians have commonly used host response biomarkers to diagnose and assess the severity of systemic infection. Most of these biomarkers, such as acute-phase proteins or cytokines, are nonspecific immunomodulating mediators of the inflammatory cascade. With advances in biochemical/genetic research, it is anticipated that future biomarkers will be 'organ and/or disease specific'. There is also the quest for discovery of 'novel' biomarkers to assist diagnosis and prognosis of neonatal diseases using powerful mass-screening techniques, e.g. the next-generation sequencing, proteomics and arrays. This article aims to introduce the concept of the next generation of biomarkers to practising neonatal clinicians, and, hopefully, to integrate basic science research into day-to-day clinical practice in the future.

Copyright $\odot 2012$ S. Karger AG, Basel
\end{abstract}

\section{Introduction}

Biomarkers in medicine enable clinicians to accurately assess patients presenting with myriad clinical signs and symptoms (i.e. diagnosis) and to predict the course and outcome of an illness (i.e. prognostication). In neonatology, the use of host response biomarkers for diagnosing neonatal sepsis has been a major area of research priority $[1,2]$. Over the past decades, neonatologists have identified immunomodulating mediators and utilized them as surrogate markers for early diagnosis and predicting the severity of systemic infection and necrotizing enterocolitis (NEC), [3-5]. With progressive advancement in biochemical/genetic research, more sophisticated classes of biomarkers are identified, including cytokines [6], chemokines [3, 4], cell surface antigens [7-9], and Gram-positive and Gram-negative organism-specific nucleic acids [10]. More recently, we have entered into a new era of searching for 'novel' as well as 'specific' biomarkers for individual diseases, organ injury, or even monitoring disease activity in a specific region within an organ. This article reviews the latest achievement in such areas and discusses future trends in searching for the next generation of biomarkers in different neonatal conditions.

\section{Conventional Biomarkers}

The past two decades have witnessed the use of increasingly sophisticated classes of mediators for diagnosis and prediction of outcome in serious neonatal conditions. One of the most important and well-studied conditions is systemic infection in neonatology $[1,2]$. As neonatal sepsis is

\section{KARGER}

Fax +4161306 1234 E-Mail karger@karger.ch www.karger.com
(C) 2012 S. Karger AG, Basel

$1661-7800 / 12 / 1022-0145 \$ 38.00 / 0$

Accessible online at:

www.karger.com/neo
Prof. Pak C. Ng

Department of Paediatrics, Level 6, Clinical Sciences Building

Prince of Wales Hospital, The Chinese University of Hong Kong

Shatin, NT, Hong Kong, SAR (China)

Tel. +852 2632 2851, E-Mail pakcheungng@ cuhk.edu.hk 
not usually confined to one specific organ, most investigators focus on up- or down-regulation of immunomodulating proteins in the inflammatory cascade as surrogate biomarkers for identifying infections or infection-related conditions such as NEC $[1,2]$. Although these proteins, e.g. interleukins and chemokines $[3,4,6]$, are not specific to a particular disease or infection, fortunately they are reasonably accurate in positively identifying neonatal infections as, apart from sepsis, there are relatively few inflammatory conditions that will substantially influence their circulating levels in term and preterm infants. For example, connective tissue and rheumatoid diseases, which often affect the immunological pathway and inflammatory cascade, do not present at such an early stage of life. However, tissue inflammation and necrosis induced by surgery can easily mask the biochemical signals of underlying sepsis. Whilst this approach can successfully identify genuine septicaemia in the majority of suspected cases, these 'nonspecific' biomarkers fail to differentiate sepsis from NEC [5], which carries different management strategies and long-term outcomes. Similarly, an increase in concentrations of pro-inflammatory cytokines in tracheal aspirate specimens of ventilated preterm infants merely signifies inflammation in the respiratory tract [11]. It does not provide precise information on the type of cell damaged or the exact location of injury. In addition, the conventional approach to validate biomarkers in most current studies is to employ the 'candidate approach' of selecting known proteins/mediators and subject them to assessment in a case-control or cohort study to work out the diagnostic utilities (i.e. sensitivity and specificity for case-control studies, plus positive- and negative-predictive values for cohort studies) [12]. This approach is efficient but limiting, and suffers from the major drawback of evaluating only archived mediators. Novel biomarkers could not be discovered with such a study design. Thus, in recent years, investigators have fine-tuned their objectives towards the discovery of novel biomarkers [13], and using new biochemical technologies for more precise identification of specific diseases or specific organ pathologies.

\section{Disease- or Organ-Specific Biomarkers}

\section{Proteins}

Specific Protein Biomarkers

The identification of circulating proteins specific for organ injury or disease has become the prime objective in biomarker research. A typical example is the use of troponin for the diagnosis of acute myocardial infarction in adults [14]. Cardiac troponins are structural proteins bound to myofibrillar filaments of the cardiac muscle. An acute increase in the circulation following myocardial injury is due to a slow release of such proteins from damaged cardiac cells. The positive correlation between circulating troponin concentration and the magnitude of myocardial injury after heart surgery or cardiotoxic drug treatment renders this class of protein useful prognostic indicators of morbidity and mortality in the paediatric age group [15]. The same principle applies to term and preterm newborns for evaluating the extent of myocardial injury in newborns with perinatal depression and those suffering cardiopulmonary compromise secondary to respiratory distress syndrome. Recent studies suggested that circulating troponin $\mathrm{T}$ concentrations were significantly higher in infants with the most severe grade (Sarnat stage III) of neonatal encephalopathy compared with those with lower grades (Sarnat stages I and II) and healthy controls [16]. Similarly, significantly higher levels of troponin T were found in perinatally depressed infants with low ejection fraction, heart failure and those who did not survive $[17,18]$. Preterm infants with respiratory distress syndrome, poor myocardial function and hypotension requiring inotropes also had elevated troponin $\mathrm{T}$ levels [19]. Troponin $\mathrm{T}$ is more cardioselective than conventional creatine kinase-MB and lactate dehydrogenase as a cardiac biomarker and undoubtedly a more precise indicator of cardiac injury.

Another example is the use of gastro-intestinal selective biomarkers for verifying enterocyte injury or cell death in preterm infants presenting with abdominal features, and differentiating life-threatening NEC from other benign neonatal abdominal conditions with similar clinical presentations such as gastro-intestinal dysmotility. Intestinal fatty acid-binding protein (I-FABP), a specific indicator of early enterocyte cell death [20, 21], is expressed by enterocytes in both small and large bowels and is liberated into the bloodstream as soon as the integrity of the enterocyte cell membrane is compromised. It is a small molecule and can readily pass through renal glomeruli. Recent studies found that the urinary IFABP:creatinine concentration ratio was disproportionately elevated in infants who developed NEC or intestinal necrosis compared with those who did not $[22,23]$. Thus, I-FABP is considered to be an organ-specific biomarker for intestinal mucosal injury and may potentially be developed as a screening test for NEC in newborns [22, 23].

Brain-Specific Proteins. Neurofilament triplet protein, glial fibrillary acid protein and S-100 were found to be 4to 200 -fold higher in infants with post-haemorrhagic hy- 
drocephalus $(\mathrm{PHH})$ than those without $\mathrm{PPH}$. All these proteins were significantly higher in $\mathrm{PHH}$ infants who had parenchymal damage, died or were disabled at 1 year of age than in those who had PHH without parenchymal lesions, survived and were without disability at 12 months of age. Other proteins in the cerebrospinal fluid, such as transforming growth factor- $\beta_{1}$, thrombopoietin or interferon- $\gamma$, are not brain specific, but their presence in the compartment is likely the result of physiological responses to intraventicular haemorrhage [24]. These proteins can reflect the inflammatory activity, extracellular matrix activity and the extent of cell death during the insult [24]. Thus, they have been used for the prediction of $\mathrm{PHH}$ and severity of brain injury [24]. Another example is the targeted assessment of different types of lung cell injury that can provide a distinctive blood biomarker profile, which enables respirologists to differentiate idiopathic pulmonary fibrosis from other causes of acute lung injury in adult patients [25].

Although investigators are progressing in the search of specific biomarkers for different diseases in neonatology, it is important: (1) to establish the normal range of the biomarker in term and preterm newborns, (2) to recognize the maturational and developmental differences in expression of biomarkers in adults, children and newborns, e.g. troponin I is not fully expressed in the neonatal myocardium until 9 months of age [26], (3) to recognize the differences in the disease spectrum between adults and newborns, e.g. acute myocardial infarction in adult patients versus cardiac ischaemia in perinatally depressed newborns, (4) to verify the influence of perinatal factors ,such as mode of delivery, Apgar scores, gestational age and use of antenatal drugs on the expression of biomarkers, and (5) to recognize the limitations of 'specific' biomarkers, e.g. systemic hypotension or septicaemic shock, which compromises the hepatosplanchnic circulation, may potentially result in the release of gut barrier biomarkers into the bloodstream without causing NEC.

\section{Nucleic Acids}

The discovery of circulating nucleic acids in plasma has revolutionized biomarker research and initiated unbounded opportunities for diagnostic and prognostic applications in all branches of medicine. The spectrum includes tumour-derived DNA in cancer research, assessment of body organ injury in traumatology, monitoring the progress of organ transplantation and non-invasive prenatal diagnosis using maternal blood samples [27].

Next Generation of Biomarkers

\section{Deoxyribonucleic Acid}

Cell-Free Plasma DNA

The greatest advantage of using circulating cell-free fetal DNA in maternal plasma is to provide direct genetic information of the fetus in a non-invasive manner. Cell-free fetal DNA constitutes about 3-6\% of total DNA in the maternal plasma. Demonstration of the Y chromosome-specific sequence in maternal plasma can accurately determine the fetal gender and is vital for the prenatal diagnosis of X-linked diseases, haemophilia [28]. Accurate genotyping of fetal Rhesus blood group in Rhesusnegative mothers has reduced unnecessary use of immunoglobulin prophylaxis and invasive amniocentesis in high-risk pregnancies [29]. This type of screening test has already been translated into routine clinical practice in some countries. Also, positive identification of the DNA sequence of autosomal dominant diseases, such as Huntington's chorea [30] and myotonic dystrophy [31], accurately indicates inheritance of the disease in the fetus, though a negative survey does not rule out the possibility of inheritance if the mother is a carrier. Further, an elevation of fetal DNA concentration in maternal blood may precede the onset of symptoms in pre-eclampsia [32, 33] and preterm labour [34], presumably due to increased fetal cellular trafficking or decreased fetal DNA clearance in pregnancies with complications $[35,36]$. Thus, recent advances in the evolution of circulating cell-free DNA as molecular biomarkers have opened up a new avenue for future assessment of inherited diseases in utero.

Our research team has also used Gram-positive and Gram-negative organism-specific nucleic acids for identifying and differentiating these two types of septicaemia in preterm infants [10]. None of the sepsis episodes were classified into the wrong Gram-specific category. More importantly, despite negative blood cultures in 5 infants suffering from intra-abdominal sepsis, the quantitative polymerase chain reaction (PCR) test could identify the Gram-specific category of the causative organisms in blood. Thus, the test is highly specific and a positive result is able to demonstrate bacterial bloodstream infection with high precision [10]. A recent study on the broadrange $16 \mathrm{~S}$ gene using real-time PCR also demonstrated that 7 infants with positive PCR results and negative blood cultures had bacterial sepsis [37].

\section{Metagenomics}

Another fast-developing technique is the use of metagenomics for molecular identification of a vast array of micro-organisms. For example, high-throughput 16S rRNA sequencing has been used to obtain specific bacterial se- 
quence signatures in stool samples for evaluating the status of the gut micro-environment of microbial colonisation. This vital information can theoretically improve the ability to diagnose and treat gut microbial-mediated conditions [38]. A recent study suggested that a significant change in intestinal luminal microbiota with upsurge of Proteobacteria and decrease in Firmicutes was observed in preterm infants who subsequently developed NEC [39]. The recognition of specific bacterial sequence signatures can lead to better understanding of the aetiology of NEC, and this technique may potentially transform into an efficient diagnostic tool or a prophylactic measure. Hopefully, neonatologists in the future may screen for foreign, e.g. viral, bacterial and fungal nucleic acids in blood samples of septicaemic babies and obtain accurate information for the identification of the causative organism plus antimicrobial sensitivity profile without the need for conventional medium culture or serological test.

\section{Next-Generation Sequencing Technique}

The development of next-generation sequencing (NGS), has substantially improved the efficiency and sensitivity of nucleic acid sequencing and detection in plasma [40]. This breakthrough in technology using maternal plasma has recently been translated into the future noninvasive screening test for detection of trisomy 21 fetuses. The principle is to show the presence of an increased amount of chromosome 21 sequences in maternal blood. The difficulty of measuring a minute increment in chromosome 21 DNA concentration has been overcome by NGS [41], which can accurately identify and quantify millions of DNA fragments in the blood sample within a short time period (days) [42]. In a multicentre study of 753 high-risk pregnancies using a designated protocol (2-Plex Protocol), Down's fetuses were detected with extremely high accuracy and diagnostic utility (100\% sensitivity, $97.9 \%$ specificity, $96.9 \%$ positive and $100 \%$ negative predictive value) [43]. It is anticipated that only a very small percentage of all pregnant women (estimated $0.1 \%$ ) will in the future require referral for chorionic villus sampling and amniocentesis for genetic confirmation [43]. The same technique may be applied for detecting other trisomies, such as trisomy 18 or 13. It is not difficult to foresee that in the near future, perinatologists will be able to perform a non-invasive genetic and mutation scans for the whole fetal genome, and maternal plasma nucleic acid sequencing will become an integral part of routine prenatal screening for genetic diseases [43]. The same principle can apply for RNA sequencing and is termed 'transcriptome analysis'.

\section{Ribonucleic Acid}

Messenger RNA

Analysis of cell-free plasma RNA offers another dimension for the development of disease-related biomarkers. The messenger RNA (mRNA) expression profile unique to a disease or tissue may be exploited as a specific diagnostic tool. The detection of circulating RNA offers a number of advantages over circulating DNA [44]. First, if an RNA transcript unique to a specific organ/tissue is chosen, this method is usually more applicable to the disease of that organ because production of mRNA depends on gene expression, which varies depending on the cell type. Secondly, quantitatively more RNA than DNA will be released from the injured cells. This is due to the fact that many copies of a RNA transcript are present in each cell, whereas only a single diploid genome equivalent of DNA is contained in one cell. In one study, liver-derived albumin $(A L B)$ mRNA was evaluated as a diagnostic biomarker for detecting liver pathologies [45]. The results suggested that plasma $A L B$ mRNA was significantly increased in patients with hepatocellular carcinoma, cirrhosis and active chronic hepatitis B compared with healthy subjects. Overall, plasma $A L B$ mRNA was significantly increased (cutoff 835 copies $/ \mathrm{ml}$ ) in $73.8 \%$ of patients with liver pathologies whereas only $21.5 \%$ had abnormal alanine aminotransferase levels. Similarly, 91.4\% patients with hepatocellular carcinoma had elevated plasma $A L B$ mRNA concentrations, whereas only $48.6 \%$ had abnormal serum $\alpha$-fetoprotein levels [45]. Much evidence has now accumulated to suggest that the release of mRNA into plasma is the consequence of cell death. Thus, plasma $A L B$ mRNA may be considered to be a more sensitive biomarker for diagnosing liver cell death than the conventional liver function test or $\alpha$-fetoprotein. In addition, the investigators have demonstrated that a proportion of the supposedly liver-specific $A L B$ mRNA detected in whole blood was in fact derived from haematopoietic cells due to illegitimate gene transcription, and that only $A L B$ mRNA detected in plasma was liver specific [45]. A similar principle of using mRNA can, therefore, apply to investigate liver disease, e.g. parenteral nutrition-associated cholestasis or other organ-specific injuries in neonatal patients.

\section{MicroRNA}

The microRNA (miRNA) molecules that circulate in human plasma are another recent discovery. This is a class of small (about 22 nucleotides) non-coding RNA fragments that inhibit gene expression, thereby halting the translation machinery that produces functional pro- 
teins [46]. As miRNA is crucial for normal operation of cellular function, aberrant miRNA expression profiles are associated with specific organ dysfunction and diseases. Consequently, miRNA has been used as a diagnostic biomarker for detecting sepsis [47], drug-induced liver injury [48], myocardial injury [49], and malignancies [50]. Investigators have also identified specific miRNAs for differentiating different diseases within an organ. For example, heart-associated miR-208b and miR-499 were increased 1,600- and 100-fold, respectively, in acute myocardial infarction due to cardiomyocyte injury [49]. This specific profile of miRNA expression may enable clinicians to differentiate patients with acute myocardial infarction from those with other cardiac conditions, such as viral myocarditis, acute heart failure and diastolic dysfunction. Also, in a separate study, intestinal region-specific miRNAs (e.g., terminal ileum- and colon-specific miRNA) have been identified [51]. The findings suggested that different miRNAs were differentially expressed in different diseases and different sites of the bowel, including ulcerative colitis, Crohn's colitis and Crohn's ileitis [51]. Thus, we may soon be able to locate precisely the site of active disease and to differentiate closely immunologically related conditions, such as Crohn's disease and ulcerative colitis, with blood biomarkers. In principle, similar techniques may also apply to newborns with NEC, thus assisting neonatologists and paediatric surgeons to locate the exact region of the diseased bowel.

Although there are advantages in using nucleic acids as diagnostic or prognostic biomarkers, there are also limitations, including: (1) a large volume of blood may be required for quantifying nucleic acids of low abundance, (2) cell-free mRNA has a relatively short half-life in the circulation as plasma is rich in nucleases, (3) expression levels of mRNA in the tissue may not necessarily correlate with the serum concentration, and (4) tissue-specific mRNA may be difficult to identify as many tissue mRNAs are also produced by circulating or infiltrating inflammatory cells.

\section{Searching for 'Novel' Biomarkers - the 'Hypothesis-Free' Approach}

The ultimate aim of biomarker research is the discovery of new and previously unreported biomarkers for clinical use. In 2010, our research team has successfully used the mass spectrometry-based proteomic profiling technology to identify known and novel host-response signature proteins, serum amyloid A and proapolipopro- tein CII, respectively, for the early diagnosis of neonatal infection and NEC [13]. Using a mathematical formula to calculate the ApoSAA score, we could confidently withhold or stop antimicrobial treatment within $24 \mathrm{~h}$ in $61 \%$ of true-negative sepsis/NEC cases [13]. In this study, a very stringent experimental design was adopted to minimize the effect of bias and the chance of identifying falsepositive candidate biomarkers. This study design is based on the fundamental principles of novel biomarkers discovery and can be considered as one of the models to which similar future studies may refer.

In the first part of the study, the profiling process consisted of two distinctive phases: the biomarker discovery phase and the independent validation phase. First, in the discovery phase, a 3-step approach was adopted: (1) An initial case-control comparison of plasma proteomic profiles between disease subjects and control subjects was used to identify the desired differential proteomic peaks. (2) These peaks would be considered as potential biomarkers only if their levels demonstrated a reversal pattern upon disease recovery in the longitudinal followup with a separate group of patients (this separate group included both disease and control cases). This essential step was to avoid selecting proteomic peaks caused by systematic bias. (3) The plasma concentrations of the identified proteins were then subjected to logistic regression analysis and a diagnostic equation was constructed. Secondly, in the validation phase, other independent groups of disease and control infants were evaluated for validating the diagnostic equation to determine their areas under the receiver operating characteristic curves. Thereafter, in the second part of the study, the selected biomarkers and equations were subjected to the final validation process using a prospective cohort of patients to determine the ultimate diagnostic utilities of the test [13]. Thus, only with such an elaborate study design could new and robust biomarkers be discovered for clinical use.

\section{Conclusion}

Advances in molecular diagnostic technologies, in particular gene sequencing and other powerful mass screening techniques, such as proteomics and arrays, have greatly opened up new opportunities for discovering new biomarkers for diagnostic and prognostic applications. A comprehensive and robust approach for biomarker discovery has been outlined in this review. The next generation of biomarkers, whether they are circulat- 
ing proteins, cell-free DNA, mRNA or miRNA, should be organ and/or disease specific. Thus, it is anticipated that future biomarkers will likely possess excellent diagnostic utilities as these tools will be target specific and/or genetically engineered.

\section{Disclosure Statement}

The authors declare that there is no conflict of interest.

\section{References}

$\checkmark 1$ Ng PC, Lam HS: Biomarkers for late-onset neonatal sepsis: cytokines and beyond. Clin Perinatol 2010;37:599-610.

$\checkmark 2$ Ng PC: Diagnostic markers of infection in neonates. Arch Dis Child Fetal Neonatal Ed 2004;89:F229-F235.

>3 Ng PC, Li K, Leung TF, Wong RP, Li G, Chui KM, Wong E, Cheng FW, Fok TF: Early prediction of sepsis-induced disseminated intravascular coagulation with interleukin-10, interleukin- 6 and RANTES in preterm infants. Clin Chem 2006;52:1181-1189.

4 Ng PC, Li K, Chui KM, Leung TF, Wong RP, Chu WC, Wong E, Fok TF: IP-10 is an early diagnostic marker for identification of lateonset bacterial infection in preterm infants. Pediatr Res 2007,61:93-98.

$\checkmark 5$ Lam HS, Wong SP, Cheung HM, Chu WC, Wong RP, Chui KM, Liu FY, Li K, Fok TF, Ng PC: Early diagnosis of intra-abdominal inflammation and sepsis by neutrophil CD64 expression in newborns. Neonatology 2011; 99:118-124

6 Ng PC, Cheng SH, Chui KM, Fok TF, Wong MY, Wong W, Wong RP, Cheung KL: Diagnosis of late onset neonatal sepsis with cytokines, adhesion molecule, and C-reactive protein in preterm very low birthweight infants. Arch Dis Child Fetal Neonatal Ed 1997;77:F221-F227.

7 Ng PC, Li K, Wong RP, Chui KM, Wong E, Fok TF: Neutrophil CD64 expression: a sensitive diagnostic marker for late-onset nosocomial infection in very low birth weight infants. Pediatr Res 2002;51:296-303.

$>8$ Ng PC, Li G, Chui KM, Chu WC, Li K, Wong RP, Fok TF: Quantitative measurement of monocyte HLA-DR expression in the identification of early-onset infection. Biol Neonate 2006;89:75-81.

$\checkmark 9$ Turunen R, Andersson S, Nupponen I, Kautiainen H, Siitonen S, Repo H: Increased CD11b-density on circulating phagocytes as an early sign of late-onset sepsis in extremely low birth weight infants. Pediatr Res 2005; 57:270-275.

$\checkmark 10$ Chan KY, Lam HS, Cheung HM, Chan AK, Li K, Fok TF, Ng PC: Rapid identification and differentiation of Gram-negative and Grampositive bacterial bloodstream infections by quantitative polymerase chain reaction in preterm infants. Crit Care Med 2009;37: 2441-2447.
11 Murch SH, MacDonald TT, Wood CB, Costeloe KL: Tumour necrosis factor in the bronchoalveolar secretions of infants with the respiratory distress syndrome and the effect of dexamethasone treatment. Thorax 1992;47: 44-47.

12 Ng PC: Clinical trials for evaluating diagnostic markers of infection in neonates. Biol Neonate 2005;87:111-112.

13 Ng PC, Ang IL, Chiu RW, Li K, Lam HS, Wong RP, Chui KM, Cheung HM, Ng EW, Fok TF, Sung JJ, Lo YM, Poon TC: Host-response biomarkers for diagnosis of late-onset septicemia and necrotizing enterocolitis in preterm infants. J Clin Invest 2010;120 2989-3000.

14 Hamm CW, Goldmann BU, Heeschen C, Kreymann G, Berger J, Meinertz T: Emergency room triage of patients with acute chest pain by means of rapid testing for cardiac troponin T or troponin I. N Engl J Med 1997;337:1648-1653.

15 El-Khuffash AF, Molloy EJ: Serum troponin in neonatal intensive care. Neonatology 2008;94:1-7.

16 Gunes T, Ozturk MA, Koklu SM, Narin N, Koklu E: Troponin-T levels in perinatally asphyxiated infants during the first 15 days of life. Acta Paediatr 2005;94:1638-1643.

17 Boo NY, Hafidz H, Nawawi HM, Cheah FC, Fadzil YJ, Abdul-Aziz BB, Ismail Z: Comparison of serum cardiac troponin $\mathrm{T}$ and creatine kinase $\mathrm{MB}$ isoenzyme mass concentrations in asphyxiated term infants during the first 48 h of life. J Paediatr Child Health 2005; 41:331-337.

18 Costa S, Zecca E, De RG, De LD, Barbato G, Pardeo M, Romagnoli C: Is serum troponin $\mathrm{T}$ a useful marker of myocardial damage in newborn infants with perinatal asphyxia? Acta Paediatr 2007;96:181-184

19 Clark SJ, Newland P, Yoxall CW, Subhedar $\mathrm{NV}$ : Concentrations of cardiac troponin $\mathrm{T}$ in neonates with and without respiratory distress. Arch Dis Child Fetal Neonatal Ed 2004;89:F348-F352.

20 Kanda T, Fujii H, Tani T, Murakami H, Suda T, Sakai Y, Ono T, Hatukeyama K: Intestinal fatty acid binding protein is a useful diagnostic marker for mesenteric infarction in humans. Gastroenterology 1996;110:339343.
21 Lieberman JM, Sacchettini J, Marks C, Marks WH: Human intestinal fatty acid binding protein: report of an intestinal ischemia. Surgery 1997;121:335-342.

22 Derikx JP, Evennett NJ, Degraeuwe PL, Mulder TL, van Bijnen AA, van Heurn LW, Buurman WA, Heineman E: Urine based detection of intestinal mucosal cell damage in neonates with suspected necrotizing enterocolitis. Gut 2007;56:1473-1475.

23 Thuijls G, Derikx JP, van Wijck K, Zimmermann LJ, Degraeuwe PL, Mulder TL, Van der Zee DC, Brouwers HA, Verhoeven $\mathrm{BH}$, van Heurn LW, Kramer BW, Buurman WA, Heineman E: Non-invasive markers for early diagnosis and determination of the severity of necrotizing enterocolitis. Ann Surg 2010; 251:1174-1180.

24 Merhar S: Biomarkers in neonatal posthemorrhagic hydrocephalus. Neonatology 2012; 101:1-7.

-25 Collard HR, Calfee CS, Wolters PJ, Song JW, Hong SB, Brady S, Ishizaka A, Jones KD, King Jr TE, Matthay MA, Kim DS: Plasma biomarker profiles in acute exacerbation of idiopathic pulmonary fibrosis. Am J Physiol Lung Cell Mol Physiol 2010;299:L3-L7.

26 Sasse S, Brand NJ, Kyprianou P, Dhoot GK, Wade R, Arai M, Periasamy M, Yacoub MH, Barton PJ: Troponin I gene expression during human cardiac development and in endstage heart failure. Circ Res 1993;72:932938 .

27 Tsang JC, Lo YM: Circulating nucleic acids in plasma/serum. Pathology 2007;39:197207.

28 Santacroce R, Vecchione G, Tomaiyolo M, Sessa F, Sarno M, Colaizzo D, Grandone E, Margaglione M: Identification of fetal gender in maternal blood is a helpful tool in the prenatal diagnosis of haemophilia. Haemophilia 2006;12:417-422.

29 Finning K, Martin P, Daniels G: A clinical service in the UK to predict fetal Rh (Rhesus) $\mathrm{D}$ blood group using free fetal DNA in maternal plasma. Ann NY Acad Sci 2004;1022: 119-123.

30 Gonzalez-Gonzalez MC, Trujillo MJ, Rodriguez de Alba M, Garcia-Hoyos M, LordaSanchez I, Diaz-Recasens J, Ayuso C, Ramos C: Huntington disease-unaffected fetus diagnosed from maternal plasma using QFPCR. Prenat Diagn 2003:23:232-234. 
-31 Amicucci P, Gennarelli M, Novelli G, Dallapiccola B: Prenatal diagnosis of myotonic dystrophy using fetal DNA obtained from maternal plasma. Clin Chem 2000;46:301302.

-32 Lo YM, Leung TN, Tein MS, Sargent IL, Zhang J, Lau TK, Haines CJ, Redman CW: Quantitative abnormalities of fetal DNA in maternal serum in preeclampsia. Clin Chem 1999;45:184-188.

-33 Leung TN, Zhang J, Lau TK, Chan LY, Lo YMD: Increased maternal plasma fetal DNA concentrations in women who eventually develop preeclampsia. Clin Chem 2001:47:137139.

>34 Leung TN, Zhang J, Lau TK, Hjelm NM, Lo YM: Maternal plasma fetal DNA as a marker for preterm labour. Lancet 1998;352:19041905.

-35 Holzgreve W, Ghezzi F, Di Naro E, Ganshirt D, Maymon E, Hahn S: Disturbed feto-maternal cell traffic in preeclampsia. Obstet Gynecol 1998;91:669-672.

-36 Lau TW, Leung TN, Chan LY, Lau TK, Chan KC, Tam WH, Lo YM: Fetal DNA clearance from maternal plasma is impaired in preeclampsia. Clin Chem 2002;48:2141-2146.

- 37 Ohlin A, Backman A, Ewald U, Schollin J, Bjorkqvist M: Diagnosis of neonatal sepsis by broad-range $16 \mathrm{~S}$ real-time polymerase chain reaction. Neonatology 2012;101:241-246.

-38 Morowitz MJ, Denef VJ, Costello EK, Thomas BC, Poroyko V, Relman DA, Banfield JF: Strain-resolved community genomic analysis of gut microbial colonization in a premature infant. Proc Natl Acad Sci 2011;108: 1128-1133.
39 Mai V, Young CM, Ukhanova M, Wang X, Sun Y, Casella G, Theriaque D, Li N, Sharma R, Hudak M, Neu J: Fecal microbiota in premature infants prior to necrotizing enterocolitis. PLoS One 2011;6:e20647.

40 Voelkerding KV, Dames SA, Durtschi JD: Next-generation sequencing: from basic research to diagnostics. Clin Chem 2009;54: 641-658.

41 Chiu RW, Cantor CR, Lo YM: Non-invasive prenatal diagnosis by single molecule counting technologies. Trends Genet 2009;25: 324-331.

42 Schuster SC: Next-generation sequencing transforms today's biology. Nat Methods 2008;5:16-18.

43 Chiu RW, Akolekar R, Zheng YW, Leung TY, Sun H, Chan KC, Lun FM, Go AT, Lau ET, To WW, Leung WC, Tang RY, Au-Yeung SK, Lam H, Kung YY, Zhang X, van Vugt JM, Minekawa R, Tang MH, Wang J, Oudejans CB, Lau TK, Nicolaides KH, Lo YM: Noninvasive prenatal assessment of trisomy 21 by multiplexed maternal plasma DNA sequencing: large scale validity study. Br Med J 2011; 342:c7401 doi:10.1136/bmj.c7401.

44 Lambrechts AC, van't Veer LJ, Rodenhuis S: The detection of minimal numbers of contaminating epithelial tumor cells in blood or bone marrow: use, limitations and future of RNA-based methods. Ann Oncol 1998;9: 1269-1276.

45 Chan RW, Wong J, Chan HL, Mok TS, Lo WY, Lee V, To KF, Lai PB, Rainer TH, Lo YM, Chiu RW: Aberrant concentrations of liverderived plasma albumin mRNA in liver pathologies. Clin Chem 2010;56:82-89.

-46 Bartel DP: MicroRNAs: genomics, biogenesis, mechanism and function. Cell 2004;116: 281-297.
47 Vasilescu C, Rossi S, Shimizu M, Tudor S, Veronese A, Ferracin M, Nicoloso MS, Barbarotto E, Popa M, Stanciulea O, Fernandez $\mathrm{MH}$, Tulbure D, Bueso-Ramos CE, Negrini M, Calin GA: MicroRNA fingerprints identify miR-150 as a plasma prognostic marker in patients with sepsis. PLoS One 2009; 4:e7405.

48 Wang K, Zhang S, Marzolf B, Troisch P, Brightman A, Hu Z, Hood LE, Galas DJ: Circulating microRNAs, potential biomarkers for drug-induced liver injury. Proc Natl Acad Sci USA 2009; 106:4402-4407.

49 Corsten MF, Dennert R, Jochems S, Kuznetsova T, Devaux Y, Hofstra L, Wagner DR, Staessen JA, Heymans S, Schroen B: Circulating microRNA-208b and microRNA-499 reflect myocardial damage in cardiovascular disease. Circ Cardiovasc Genet 2010;3:499-506.

50 Mitchell PS, Parkin RK, Kroh EM, Fritz BR, Wyman SK, Pogosova-Agadjanyan EL, Peterson A, Noteboom J, O’Briant KC, Allen A, Lin DW, Urban N, Drescher CW, Knudsen BS, Stirewalt DL, Gentleman R, Vessella RL, Nelson PS, Martin DB, Tewari M: Circulating microRNAs as stable blood-based markers for cancer detection. Proc Natl Acad Sci USA 2008;105:10513-10518.

-51 Wu F, Zhang S, Dassopoulos T, Harris ML, Bayless TM, Meltzer SJ, Brant SR, Kwon JH: Identification of microRNAs associated with ileal and colonic Crohn's disease. Inflamm Bowel Dis 2010;16:1729-1738. 